University of Nebraska - Lincoln

DigitalCommons@University of Nebraska - Lincoln

Sociology Department, Faculty Publications

Sociology, Department of

1999

\title{
Multiple Perspectives on Multimedia in the Large Lecture
}

Helen A. Moore

hmoore1@unl.edu

Timothy D. Pippert

University of Nebraska-Lincoln

Follow this and additional works at: https://digitalcommons.unl.edu/sociologyfacpub

Part of the Educational Sociology Commons

Moore, Helen A. and Pippert, Timothy D., "Multiple Perspectives on Multimedia in the Large Lecture" (1999). Sociology Department, Faculty Publications. 148.

https://digitalcommons.unl.edu/sociologyfacpub/148

This Article is brought to you for free and open access by the Sociology, Department of at DigitalCommons@University of Nebraska - Lincoln. It has been accepted for inclusion in Sociology Department, Faculty Publications by an authorized administrator of DigitalCommons@University of Nebraska - Lincoln. 


\title{
Articles
}

\section{MULTIPLE PERSPECTIVES ON MULTIMEDIA IN THE LARGE LECTURE*}

\begin{abstract}
Students, graduate instructors, and a professor responded in journals, on objective tests, in focus groups, and on survey questionnaires to the effects of computer multimedia in four large lecture classes. Graduate instructors and students responded in focus groups to multimedia technologies with consistent themes, including enhancement of cognitive strategies (note taking and organization of ideas) and motivation. However, students also expressed distancing from the instructor. Surveys of the same student groups and a journal kept by the course professor reflected similar themes. Student achievement outcomes (pre-and posttest scores) showed no differences across two classroom applications of multimedia presentations: static and dynamic. Sociology instructors should consider adopting more complex computer multimedia in light of balancing interests: (1) resource scarcity in education and (2) few direct demonstrable effects of media on objective measures of student test outcomes in this and other research. However, our participants consistently cite considerable enhancement of students' cognitive skills and motivations (especially note taking and student interest levels), and our instructors endorse the positive effects of multimedia development on the process of reworking and rethinking their course curricula and materials.
\end{abstract}

\section{Timothy D. PipPerT \\ University of Nebraska-Lincoln}

WHAT DO WE KNOW as teachers and learners about multimedia technology and its use in the classroom? Multimedia are the forms or vehicles by which instruction is formatted, stored, and delivered to the learner. "What we know" about multimedia usually depends upon our differing roles in the classroom. To assess the outcomes of multimedia use in large lecture classes more accurately, we sought the perspectives of students, graduate instructors, and two professors from four mass introductory sociology classes. This paper describes the instructional functions of multimedia presentation software, especially

*We extend our thanks to Dr. David Brinkerhoff for comments on an early draft of this manuscript and to three anonymous reviewers for Teaching Sociology who made many useful suggestions for our revisions. Please address correspondence to Timothy Pippert at the Department of Sociology, University of NebraskaLincoln, Lincoln, NE 68588-0324; e-mail: tpippert@unlinfo.unl.edu

Editor's note: The reviewers were Lisa BondMaupin, Amanda Konradi, and William Breedlove.

\section{Helen A. Moore University of Nebraska-Lincoln}

its potential to enhance student learning and expand our awareness of teaching and learning processes in large lecture classes.

We are interested in the application of a multimedia presentation program in large lecture classes at a research university enrolling about 18,000 undergraduates. Does the introduction of a presentation program impact student outcomes, such as perceptions of the large lecture? Are other traditional student outcome measures, such as test scores, affected? How do graduate instructors and professors in charge of multisection courses respond to the construction and practice of multimedia presentations? Are student motivations to attend to course materials enhanced by the use of multimedia, and if so, do the dynamics of the multimedia (sound, color, or movement) influence these motivations?

Several decades of research have focused on emergent instructional technologies of television, audio (tapes and radio), traditional overhead and film or video presentations, and now computer presentation pro- 
grams. Most researchers conclude that the use of multimedia can become an end in itself, without substantial evidence that it greatly enhances student-learning outcomes (Clark 1983; Clark and Salomon 1986). Educators can become more focused on computer technologies in the classroom because public figures external to the schools call for students to be prepared for a technological society. Business leaders are adamant that employees be computer literate, and computer and multimedia entrepreneurs export their technology into the classroom to develop new consumers among instructors and students. Yet the baseline question must be whether multimedia can enhance the classroom environment and outcomes for learners. For sociology instructors, these more general issues merge with our specific efforts to use computer multimedia to enhance student learning in our discipline.

To answer our questions, we sought multiple perspectives on responses to multimedia because each group-students, professors, and graduate instructors-has a unique niche in the classroom. The professors frame the multimedia programs aimed at students in large lecture halls and define the pedagogical lesson plan. The graduate instructors bridge the roles of teacher and student as they link small-group discussions to large lecture presentations. Students bring different motivations to attend to the materials at hand, different learning styles that may or may not mesh with multimedia teaching and passive lecture formats, and different levels of familiarity with large lecture halls. We question whether investments in new technology in the classroom ensure positive outcomes for any or all of these classroom participants.

\section{UTILITY AND EFFECTIVENESS OF MEDIA IN EDUCATION}

In 1992, Persell noted that "Little research systematically examines the pedagogical value of using computers in a lecture/discussion course...perhaps because such use is relatively new" (p. 92). Unfortunately,
Persell's statement concerning research on instructional technology still holds true today. Current academic attention focuses on the general possibilities of multimedia, the implementation of individual computer-aided instruction, and the evaluation of software designed for specific courses. In fact, many articles on the subject merely introduce novel media approaches. For example, Lee and Oulman (1991) and Persell (1992) offer extensive descriptions and advice on the advantages and pitfalls of using presentation software such as HyperCard and Storyboard Plus 2.0. King (1994) outlines an approach to electronic discussions in small enrollment courses. None of these empirically evaluate student outcomes. Persell (1992) does address student reactions to the use of computer technology in the classroom, but only offers anecdotal evidence. King (1994) also refers to her student evaluations of the course to assess responses.

In a general discussion of the possible student benefits of new instructional technology, Pintrich et al. (1993) identify cognitive and motivational components. These include learning skills and strategies and the goal orientations and levels of interest that can increase educational achievement among college students. Computer media instruction in large lectures might enhance such cognitive strategies as note taking, highlighting, reviewing, selecting study materials, and building interconnections among ideas or concepts (Spencer 1996). Computer-aided instruction might increase student goal orientation by providing focused materials and by increasing the general student attention level in the lecture hall (Pintrich et al. 1993).

Efforts to enhance these outcomes for students, such as comparing traditional oral classroom instruction with instruction using computers and other media, tend to focus on individual computer-aided instruction (e.g., Neapolitan 1989; Reed-Sanders and Liebowitz 1991) or software designed for specific courses (Dimitrovia, Persell, and Maisel 1993). Such studies show mixed results. Clark's review essay (1983) of research on 
multimedia effects on student learning outcomes shows only minimal enhancements, and in many studies, it shows no increase in student achievement. Yet, Spencer (1996) and others continue to posit the probability that multimedia will improve student retention of materials. Magnuson-Martinson's (1995), Stoloff's (1995), and Ansorge and Wilhite's (1994) research do reflect on the effects of introducing computer multimedia into lecture classes. Their analyses showed no increases in student test scores, while their surveys of student perceptions showed positive ratings for student goal orientation and learning strategies.

Magnuson-Martinson (1995) evaluated whether incorporating various "computerized activities" in several sociology classes would impact students' performance, impressions of the class, and retention levels. His multimedia introductions included the use of an "electronic blackboard" and a variety of software packages for individual use in laboratories. Using experimental and control groups, he pretested academic skills and attitudes, and then he evaluated student outcomes and impressions through software evaluation surveys, multiple-choice examination scores, and course evaluations. Concluding that student outcomes were "rather ambiguous," Magnuson-Martinson did not find any significant and consistent differences in the measured student outcomes and attitudes between experimental and control groups. Using psychology classes as the venue, Stoloff (1995) found no improvement, but also no decline, in student test scores when computer-aided instructional modes were introduced into the large lecture setting. Clark and Salomon's (1986) overall conclusion about past research is similar:

Research on media has shown quite clearly that no medium enhances learning more than any other medium, regardless of learning task, learner traits, symbolic elements, curriculum content, or setting. This suggests that future media selection decisions should be based on appeal and efficiency, rather than presumed learning benefits. (P. 474)
Ansorge and Wilhite (1994) surveyed students from seven different courses that used new computer-based multimedia technologies. Over half of the students reported that computer multimedia stimulated their interest in the subject matter, helped to clarify materials, enhanced the organization of class materials, and facilitated note taking. These student perceptions of their own motivation and learning experiences suggest that computer multimedia may have positive learning outcomes that are not directly measured by tests of knowledge.

Clark and Salomon (1986) argue that in most studies, the potential effects of a medium's generic attributes are unsuccessfully distinguished from the effects of the medium's introduction. Many studies fail to identify and manipulate specific media attributes and therefore miss the goal of demonstrating their differential effects. Novelty is one important source of confounding effects in past studies, with research showing a decrease in student outcome differences between media and conventional treatments over time (Kulik, Bangert, and Williams 1983). Any technology might improve learning only because it generally requires the instructor to rework and rethink his or her instructional materials, and the novelty might engage learners. Few increases in learning or motivation are sustained over time after the introduction of new media. Thus, Clark and Salomon (1986) conclude that at best we should illuminate the process and effects of media introduction, focusing on direct outcomes for students. Most research fails to address the effects of novelty for instructors who are also novices in using multimedia technology.

Clark and Salomon (1986) raise ethical questions about investing scarce educational resources into new media development. Schools historically adopt media innovations as a response to commercial and community interests, rather than as a result of identified need. "Consequently, decisions to adopt them occur before there is clear evidence about their efficacy or the availability of superior materials" (p. 475). Enthusiasm for 
computers lends "a certain currency and legitimacy to schools"(p. 475), but reduces resources for other priorities.

When we modeled critical reflection through multimedia presentation, we intended to engage our students with dynamic materials that create "perspective transformation." One of the authors of this research, Moore (the fall semester professor), constructed Microsoft PowerPoint materials (a software presentation package) specifically to highlight these pedagogical goals, not merely to provide definitions of concepts or an outline of the lecture. Chief among these pedagogic goals was enhancing students' critical reflection; "io question the validity of a long-taken-for-granted meaning perspective" (Mezirow and Associates 1990:12). Spencer (1996) asserts the large and direct value of pictorial-mode approaches on learning that move from "decorational" illustrations to "representational, organizational and interpretational" illustrations (p. 136). Moore adopted these illustration approaches to multimedia as opposed to an "activity" approach involving "hands-on" computer usage, given the inability to ensure that all 500 students had computer access.

We need to assess how or if computer media might support instructional objectives and learning outcomes, how teachers perceive the role of multimedia in the classroom, and whether already overburdened schools and faculty members should accommodate the demands for newer media. In this research, we address the effects of using PowerPoint as a lecture aid in large classes. We collected and analyzed data during the 1996 to 1997 academic year in four large introductory sociology classes that each contained 250 students. We use conceptual markers of student outcomes similar to past research: test scores as a measure of learning, and evaluation surveys as measures of attitudes and motivations. To this past research, we add multiple methodologies to triangulate on student and instructor outcomes, including focus groups with students and instructors and content analysis of the professor's teaching journal.

\section{RESEARCH METHODS}

To assess the positive and negative aspects of multimedia in the large lecture class, we triangulated information from several sources, methodologies, and classes taught under two different professors on one campus at different points in the teaching process. Using a variety of methods, we gathered information from students in four introductory sociology classes during the fall and spring semesters of the 1996 to 1997 academic year, as well as from the graduate instructors for the courses and the professor. We interviewed randomly selected students using a focus-group format, and one professor kept a detailed journal throughout the fall semester while using software-supported multimedia for the first time. A survey of student assessments and an evaluation of student pre- and postexamination scores were collected under two different applications of the multimedia presentation software package.

We used PowerPoint presentation software to produce both static and dynamic overhead presentations. Static involved essentially fixed overheads of lecture outlines and graphics. Dynamic presentations incorporated movement of the slide design elements, changing colors, and audio and video multimedia. For example, in a dynamic mode, multimedia for one lesson plan first showed a video clip on infant mortality rates among low-income populations in the United States (with a focus on Native American maternal and infant mortality rates), and then presented a set of PowerPoint elements that contrasted a medical perspective to a conflict-social model perspective on prenatal care availability and childbirth practices in the United States. The conceptual materials were contrasted through color and movement formats using PowerPoint computer slides. In a static mode, the outline of the PowerPoint elements was shown on a traditional overhead. The video clip was shown from a stand-alone VCR machine. 
Focus groups were conducted with students from two more large classes, with a different professor who also used PowerPoint as a lecture aid in the spring semester. However, this professor's presentations did not vary between static and dynamic modes. The graduate instructors for both semesters were the same pool of individuals, and during the spring semester they were asked in focus groups to reflect on the introduction of computer multimedia.

The University Institutional Review Board approved survey questionnaires and the formats for data collection. The course, classroom, and multimedia equipment available to the two professors remained constant over the semesters. The professor in the spring classes also had access to the multimedia presentations created by the fall 1996 professor.

Paying heed to Clark and Salomon's (1986) warning about untangling novelty effects from variations in media, we systematically surveyed perceptions and learning outcomes in classes during the second half of the fall semester. Initially, we gave students objective examinations on the lecture and text materials, since they were exposed to the same multimedia presentations by the same professor (more static in nature). In the latter two quarters of the semester, these two lecture sections were then exposed to either static or dynamic computer multimedia presentations. We surveyed students in the two sections to gather their perceptions of the use of multimedia under the different conditions, including questions on student motivation (Did the multimedia hold their attention? Would they purposefully select another course using multimedia?) and student skills (Did the multimedia assist in taking notes? Clarifying concepts? Improving memory?). We also administered standard tests of knowledge of the course and lecture materials, and student focus groups provided feedback on student perceptions of skills and motivations. Figure 1 illustrates the sequence for collecting fall semester data and interviews.

We then examined group differences in
Figure 1. The Sequence for Collecting Fall Semester Data

\section{Time 1 Time 2}

Class A (Late fall 1996)

Dynamic Static

Perception surveys

$\mathbf{x X}$

Learning tests

$\mathbf{x x}$

$\mathbf{x x}$

Focus group interviews

$\mathbf{x x}$

Class B (Late fall 1996)

Dynamic Dynamic

Perception surveys

$\mathbf{X X}$

Learning tests

$\mathbf{x X}$

$\mathbf{x x}$

Focus group interviews

$\mathbf{x x}$

fall semester students for: (1) student scores on performance-based tests of classroom knowledge, and (2) survey items evaluating students' perceptions of their own skills and motivations. We administered these tests and surveys during the fall course in the two sections exposed to different classroom multimedia techniques. The use of t-tests examined the hypothesis of different outcomes between sections, based on the multimedia formats (static and dynamic):

Null Hypothesis 1: Students exposed to static overhead technology will achieve similar scores on a standardized knowledge test as students in a dynamic multimedia model.

Null hypothesis 2: Students exposed to static overhead technology will have similar perceptions as students exposed to a dynamic multimedia model on the following dimensions: improved organization, note taking, level of interest and attention, clarification of information, and memory.

Our statistical criterion for t-test significance was a one-tailed test because we hypothesized that dynamic modes would produce increased student scores on cognitive and motivational factors.

Focus Groups and Journal Entries: Qualitative Measures

Since the goal of the project was to go 
beyond the data produced in student surveys and classroom test results, we implemented a substantial qualitative element to produce differing perspectives. Moore kept a teaching journal as a first-time user of PowerPoint throughout the fall semester as she taught the two lecture courses. She maintained the journal to identify her pedagogical assessments of improvements to make in the multimedia technology in the future and her personal responses to the daily teaching process.

Following the advice of Henderschott and Wright (1993), we employed focus groups to uncover student perceptions of their experiences. According to Berg (1995), more issues and topics can be addressed in discussions generated in focus groups than in individual conversations. We drew a random sample of students from the two fall 1996 course rosters and contacted them by letter for a series of comparative focus-group interviews by a graduate student who was not involved in teaching the class. During the spring of 1997, focus groups were conducted with students during 2 of the 10 recitation sections. We drew focus groups from the four classes in both semesters to determine if student impressions varied greatly between professors or between two specific conditions of fall semester computer presentations: static and dynamic. All totaled, 4 focus groups were conducted with 35 students.

Five of the six graduate instructors (who were constant across the four courses) were interviewed in focus groups in the spring of 1997. We used a semistandardized interview format to concentrate on student and graduate instructor assessments of the delivery and impact of instructional technologies (see the Appendix for focus-group questions). The focus group interviews were recorded and transcribed.

Tim Pippert, the other coauthor of this article, qualitatively analyzed both Moore's journal and the various focus-group transcriptions to identify common themes as well as impressions unique to each group's position in the classroom. He used multiple initial and analytic coding passes to determine recurring themes. The end product was similar to Lofland and Lofland's (1995) concept of a focused set of codes. These codes were arranged along the similar and contrasting impressions of a multimedia presentation software's application in the large lecture. The themes included: cognitive aspects, hardware/software issues, student learning and motivation, classroom atmosphere, classroom enhancement, motivation to use multimedia, and the pitfalls associated with computer-generated presentations.

\section{RESULTS}

\section{Perceptions of Multimedia}

While the professor, graduate instructors, and students have different positions in the classroom, discussing multimedia presentations with each group and reviewing journal entries revealed some shared impressions and concerns. Each group discussed the aesthetics of the presentations. Students enjoyed the lights and motion that are unavailable when using conventional overheads. The added "special effects" helped to capture their attention and maintain their interest. The graduate instructors mentioned not only the effects of color, sound, and motion on student interest levels, but also how multimedia presentations professionalized their classroom lectures. A number of graduate instructors felt that creating highly technical presentations would gain professional respect from students who were often only a few years younger than them.

Effective use of class time and organization also appeared to be a positive aspect of lectures using multimedia. Students and graduate instructors mentioned how concise overheads with clear points and subpoints made the lectures and the course flow in a more organized fashion. One student explains:

It (multimedia) allows the professor to know where he/she is supposed to be going. They know that by the end of the class period they need to cover these topics. That way he/she doesn't go off on one single thing and not get back to what he/she needs to be talking about. 
Numerous students mentioned that the organization and flow of a lecture, along with the use of charts and graphs, acted as an aid in helping them take better notes and in enhancing their grasp of sociological concepts. When discussing how the professor distinguished between points and subpoints by using different colors, a student commented: "With the change in colors you are able to notice the different sociological concepts and compare it to a different one. I think it helped me a lot."

As a sobering counterpoint to the instructor's emphasis on using multimedia to highlight points for critical reflection and to transform student critical thinking, one student joked that:

It (multimedia) gives me time to kind of take a power nap and then wake up and still have the stuff on the screen and be able to write it all down. I don't have to stay awake to figure out exactly what the instructor wants me to write down.
These contrasting quotes suggest that multimedia can connect students to active, comparative classroom learning, while other students will view the slides as a passive "show."

Student perceptions of multimedia were more broadly captured by use of the fall course surveys, with 203 students attending and responding during the fourteenth week of instruction (see Table 1). A t-test of item scores showed no significant differences between sections on any items, with the exception of course attendance. Students present in class $B$ (after receiving the dynamic presentations) reported a substantially higher attendance rate $(\mathrm{p} \leq .01)$. This class met at 10:30 a.m. and may merely have captured students from the 9:30 a.m. class who drifted in later. ${ }^{1}$

Responses to the various items indicated that students rated multimedia most highly for (1) effective use of time, (2) generating strong interest in the class, (3) learning about society in general, (4) learning socio-

Table 1. Average Student Evaluation Ratings

\begin{tabular}{lllll} 
Question & \multicolumn{2}{l}{ Class A (Fall $1996, \mathrm{n}=94)$} & \multicolumn{2}{c}{ Class B (Fall 1996, $\mathrm{n}=109)$} \\
\hline Time use effective & 3.35 & $(\mathrm{sd}=0.88)$ & 3.27 & $(\mathrm{sd}=0.92)$ \\
Instructor available? & 3.08 & $(\mathrm{sd}=0.85)$ & 3.04 & $(\mathrm{sd}=1.04)$ \\
Media hold interest & 3.24 & $(\mathrm{sd}=1.10)$ & 3.21 & $(\mathrm{sd}=0.93)$ \\
Learn about society & 3.53 & $(\mathrm{sd}=1.05)$ & 3.43 & $(\mathrm{sd}=1.09)$ \\
Learn concepts & 3.45 & $(\mathrm{sd}=0.91)$ & 3.28 & $(\mathrm{sd}=0.90)$ \\
Media understood & 3.96 & $(\mathrm{sd}=0.82)$ & 3.82 & $(\mathrm{sd}=1.08)$ \\
Media assist notes & 3.53 & $(\mathrm{sd}=1.26)$ & 3.41 & $(\mathrm{sd}=1.34)$ \\
Media clarify theory & 3.12 & $(\mathrm{sd}=0.95)$ & 2.90 & $(\mathrm{sd}=1.06)$ \\
Media improve memory & 2.98 & $(\mathrm{sd}=0.89)$ & 2.88 & $(\mathrm{sd}=0.99)$ \\
My class attendance & 4.08 & $(\mathrm{sd}=0.89)$ & 4.36 & $(\mathrm{sd}=0.83)^{*}$ \\
Prefer multimedia & 3.68 & $(\mathrm{sd}=1.20)$ & 3.59 & $(\mathrm{sd}=1.47)$ \\
Overall evaluation/course & 3.24 & $(\mathrm{sd}=0.94)$ & 3.13 & $(\mathrm{sd}=0.97)$ \\
Overall evaluation/instructor & 3.24 & $(\mathrm{sd}=1.15)$ & 3.45 & $(\mathrm{sd}=1.06)$ \\
\hline
\end{tabular}

Note: Student ratings of items with a score of $5=$ Excellent and $1=$ Poor.

${ }^{*} t$-test level of significance for a one-tailed test $(t=1.732, \mathrm{p} . \leq .05)$.

\footnotetext{
${ }^{1}$ One anonymous reviewer suggested that we run a panel regression to examine how presentation mode might affect changes in test scores, regressing the student test score at time two onto the test score at time one, with a dummy dependent variable for mode of presentation (dynamic $=1$; static $=0$ ), while controlling for test-related student variables. We did not tie student test scores to additional control variables
}

in our data set so a complete analysis was beyond our capability. A regression of test scores at time one and time two on the mode of presentation yielded no significant effects for the model $(\mathrm{R} 2=.013, \mathrm{p}<.252)$. However, we recommend such a strategy for those who design tests in the future to contrast pedagogical designs in the same classroom. 
logical concepts, and (5) assisting with note taking. These responses generally support elements highlighted by the focus groups of students and graduate instructors.

Those items rated substantially lower included the use of the multimedia to clarify students' understanding of theories and concepts and improvement of their memory. Students described multimedia materials as less helpful in boosting their understanding of the more abstract theoretical models used in introductory sociology (substantively comparing applications of conflict, functionalist, and symbolic interaction perspectives). In contrast, however, students rated much higher the more general item about the course helping them to learn "perspectives, principles, concepts, or theories." Students rated the multimedia as clarifying theories at 3.12 and 2.90 , respectively, while they rated the general lecture course at 3.45 and 3.28 respectively in "helping them to learn perspectives." The presentation of more abstract ideas under the rubric of "theory" may be a more difficult application for computer multimedia.

\section{Student Learning}

Using a standardized set of examination questions drawn from the textbook test bank and items designed to test materials unique to the lectures, we compared the two fall 1996 classes of students with 50-point, multiple-choice examinations at two time points. These exams were the third and fourth unit exams given in the course. Thus, all students were familiar with the examination structure, the questions reflected similar levels of difficulty, and the questions were randomly selected across chapters and lecture materials. Test scores for the two groups were not significantly different prior to, or after, the use of the static and dynamic course formats (see Table 2). The research upheld the null hypothesis that student scores will not differ by sections reflecting different multimedia styles. Note that we do not test for the "novelty" factor raised in Grove and Salomon's work (1986). All classes received some, though differently structured, multimedia teaching strategies, and all evaluations occurred after "innovation" effects would have worn off.

\section{Multimedia and Motivation}

Students learn in different ways and have different motivations to learn. All the audiences thought the multimedia presentations were an excellent way to stimulate students who are visual learners. One graduate instructor described the inclusion of sound, movement, pictures, and lectures as adding to "a complete experience" that uses almost all senses. Most students agreed. Discussing the experience, one student mentioned:

I am an education major and it has been proven over and over that the better the visuals you use, the more effective the kids learn from the material. I mean it has been proven over and over...I think it is more important to get visual impact and I think the technology helps that.

Students and graduate instructors discussed the ability of multimedia presentations to keep students' attention with a variety of colors and graphs. Are multimedia presentations educational tools or simply

Table 2. Comparison of Test Scores Across Instructional Delivery Modes

\begin{tabular}{lccc} 
& Average Test Score & t-test & Significance \\
\cline { 2 - 4 } Class A (Fall 1996) $(\mathrm{n}=223)$ & 35.24 & & \\
Dynamic (Test 3) & 35.04 & 2.464 & not significant \\
Static (Test 4) & & & \\
Class B (Fall 1996) $(\mathrm{n}=237)$ & 35.55 & & \\
Dynamic (Test 3) & 34.32 & 2.056 & not significant \\
Dynamic (Test 4) & & & \\
\hline
\end{tabular}

Note: Average student test scores from a total of 50 items. 
entertainment for the "MTV generation?" The focus groups agreed that multimedia presentations definitely act as an educational tool. Although emphasized as an educational tool, many students described multimedia as an important classroom entertainment component. One student described the connection: "If you can entertain them [students], you can capture their interests. They are going to learn what they are interested in."

These comments and survey findings reflect a general consensus among participants that multimedia programs should be continued. Continued use, however, does not mean use at the present level of technology. The professors, graduate instructors, and most students recognized that instructors must keep up with the technology. Students expect advances in classroom technology and will soon see computer-generated static overheads as commonplace, if not just as "boring" as conventional overheads. We found no significant differences in the responses of students exposed to static versus dynamic overheads. Yet, one graduate instructor noted: "If everybody just keeps using outlines, it is going to be like doing overheads again. People are going to get used to it." When asked if multimedia presentations help keep students more interested, one student responded: "I think maybe the first couple of weeks. But I think at some point you get used to it. I mean, it isn't that big of a thing, really." As noted in past research (Clark and Salomon 1986), the effect of innovation wears off rapidly in the classroom. Students not only learn content, but assimilate formats rapidly.

While the majority of students and graduate instructors saw instructors keeping up with the technology in a positive light, some articulated dissenting opinions. According to one student:

I think a lot of professors just get a kick out of having this high-tech stuff that they can show everything they want to and they try to cram more stuff that they really don't need to show or nobody cares about.

While students, graduate instructors, and professors all shared some similar impressions of the positive aspects of multimedia, no one individual was perfectly happy with the trial run. The theme of the interviews and journal entries could easily be titled "I like it but..." Moore's journal described the construction of multimedia as a developmental process. Presentations take a significant amount of time to construct (two to three hours at first), and professors must achieve confidence with the technology before they can add movement, audio, and enhanced graphics to static overheads. The gradual process of adding "bells and whistles" to the program, as well as goals for the presentation improvement, were a central theme throughout the journal entries. Graduate instructors and students commented on the gradual process and on the increased detail and creativity added to the fall courses. One graduate instructor explained:

We should explore more possibilities. Instead of overheads and presentation programs, we can use it (multi-media [sic] capabilities) to bring stuff in from the Internet. The real latest news, sounds and motions. Because those things capture the attention of the students.

Many students described a lack of technological aptitude among instructors as a problem. According to one student who had other classes that used multimedia:

In this class it (multimedia) doesn't get used as effectively as it could. Maybe that is because the instructor doesn't know how to use it as well. Maybe becoming more familiar with it could help.

While many students understood the difficulty of operating such equipment, others were quite adamant that instructors should be experts in the operation of instructional technology before using it in the classroom. One student describes the four classes he took where the instructors used multimedia:

I hate all the time it takes for the professors to get it (multimedia) started. Or in the middle of class when they want to do something with the multimedia but they can't figure out how to get 
started. And then a lot of them (instructors) don't take the time to ask somebody, so they come back the next class period and don't know any more about it.

\section{Distanced Learning}

The perceived "downside" of multimedia, reflected in the focus groups, surveys, and journal entries was that the technology tied the professor to the front of the classroom and distanced students. The lowest rated element on the fall student survey was the "professor's interest in the students, including availability for questions and consultations." Table 1 shows that students rated this item as approximately only "average" and substantially below most other student responses. The professor's journal reflected on this low rating of her interest in students as the most personally challenging element in her shift to a multimedia format. Many structural constraints of multimedia exist. Moore commented that she normally had a 10-minute break before lecture started during which to "breathe down the neck" of the prior instructor (who was removing disks, picking up materials, and relinquishing the multimedia podium). The effective set-up time was less than seven minutes, during which she had to ascertain if all hardware and software on the podium were available and in working order. Loading diskettes and setting up more traditional modes of multimedia (overhead projectors, video machines, etc.) also consumed considerable time.

Each day was an "adjustment." On any given day, two of the four major media (VCR, computer-based overheads, transparency overhead, and the opaque projector) were likely unavailable or had a "virus." Sometimes machinery was electronically shut down, which then required entering a series of numeric codes and programs. During the tenth week Moore wrote:

We are past the half way point and I noticed...a gradual move toward less and less in-class interaction with the students. It seemed that at the beginning of the semester I had enough time to stop and interact-ask questions-draw out activity. Now I seem to be doing little, if any, of that. Students are still coming up to me before and after the lecture with questions, but I seem to have less time/patience for those questions as I struggle to set up the next slide session, fiddle with the VCR, etc. This may make me less approachable as well. Thank goodness for the teaching assistants!

Once the multimedia were "in place" and ready to go, the instructor had to prepare the audio for the lecture. This included microphones on the podium and a battery-based travel microphone. Often the microphones were "dead," which required a hurried search for battery replacements and installment. As explained in Moore's journal, when she walked about three rows back into the classroom, she would "hit a microphone wall" where feedback blared across the audio system. This restricted her movement. This circus of events created a highly charged environment each day.

The graduate instructors recognized the microphone wall and understood that running the technology kept the professor tied to the podium. The "crisis" environment coupled with the short tether on the microphone kept the professor at the front of the classroom. The constant use of computer overheads likely depersonalized the lecture overall. The computer became the visual focus of the presentation and the outlines and concepts the major voice.

Student feedback from evaluations did reflect their alienation from the professor on a personal level, but the students did not associate the lack of interaction during and between classes with the technology. Several students stated that they could not ask questions in class because both professors had a certain amount of material to cover. They seemed to pin the lack of interaction with each professor on the large class size, the amount of material, and an inaccessible professor, rather than multimedia presentations.

Students in the focus groups emphasized that they expected to find little interaction in the large lecture halls. Enrolling in a mass introductory course seemed to be synony- 
mous with feeling alienated, bored, not asking questions, and practicing passive note taking. A student in a spring class explained this reluctance to ask questions in large lecture halls:

Student: I think in most lecture halls the professor never really stops lecturing. When somebody is brave enough to ask a question, usually their hand is up for three of four minutes before they are even acknowledged. But usually questions are answered respectfully.

Interviewer: Where do you get your questions answered?

Student: In recitation. Or I ask a friend.

Interviewer: Why don't you ask questions in the large lecture?

Student: Basically I don't want to interrupt him (the professor) and make him go back to something we have already gone over. Or I am just not brave enough, I guess.

Interestingly enough, each group viewed technology's influence on the lack of interaction between the professors and students in a different light. The professors and graduate instructors were acutely aware of the technological constraints as a barrier to interaction between students and professors, but students' responses were less clear about this effect of technology.

In the focus groups, however, students offered ways to increase the contact between students and professors. They suggested that multimedia presentations include breaks where the instructor shuts off the presentation and students receive encouragement to ask questions. They also suggested that the instructors use the multimedia presentations to create more interactive exercises in class and use them with other forms of multimedia such as video clips for students' comments.

In short, multimedia presentations in large lecture halls do not solely address the central problems of alienation and passivity associated with large classrooms. McGee (1991) points out some common causes:
The student member of such a (mass) course does not experience participation in a class; he or she is not psychologically a member of a class, but of an audience.

Almost everything about the mass course works to produce this phenomenon: the rooms it meets in, the rigid advance timing of the schedule, the social distance between the instructor and student. (P. 19)

\section{VARIOUS PERSPECTIVES}

Our research notes no differences in learning outcomes (test scores) across the static and dynamic classroom applications. We do find similar thematic responses from professors, graduate instructors, and students to using computer-based multimedia. However, each group has unique impressions from their distinctive classroom positions, and we examine these perspectives below.

\section{The Professor's Perspective}

Moore's detailed journal of impressions throughout the first semester included insights on the technological aspects of multimedia presentation construction. All classes were taught in a lecture hall containing all the recent computer wizardry. Not only was the room equipped with three computers, online capabilities, microphones, and video overheads, but more traditional multimedia tools such as conventional overheads and televisions were available. Because equipment was linked through one computer, simple activities such as dimming lights and bringing down a video screen or adjusting the podium became a complicated process. One journal entry highlighted how an attempt to access the VCR controls took five minutes. Technology can, in fact, be overwhelming in the classroom. On the day of the first exam, Moore's journal entry reads: "It is almost a relief not to have to fool with the machinery for a day."

Her journal cites the positive aspects of multimedia more often than the negative aspects. For example, preparing multimedia presentations forces a reworking of many aspects of the class. This is a time- 
consuming process, but one that encourages substantive course development. Multimedia programs, according to Moore's journal, expand on the instructor's ability to try new and innovative techniques and materials in the classroom. The journal contains several ideas for improvements for future classes. For example, during the seventh week she recorded:

Using the presentation software has made me go back and rework some conceptual models I have used in the past. For example, in contrasting welfare and wealthfare I was able to link those slides to the data presentations on who received government subsidies and under what social conditions. I would like to include a short video clip contrasting someone filling out forms/going through an interview at Social Services with lobbyists and legislators working on tax reforms for business/agriculture. Just to give the students a sense of the social context differences between the two. Now I can keep a lookout for such clips and figure out how to put them into the multimedia package for future use.

On a practical level, using multimedia programs requires additional reviews for errors and computer glitches. This prods the professor into a review just prior to each class. She wrote about a "layering" process of mastering one aspect of the technology at a time and adding in more technology as time progressed. Some technologies, such as online access to the Internet, were held off for the next time the course is taught or until a multimedia technology assistant is available to help prepare course materials.

\section{Graduate Instructors' Views}

We interviewed graduate instructors because of their unique position in the mass introductory classroom. As graduate teaching assistants, they attend the lectures and then work with smaller numbers of students once each week. The introductory sociology classes under review had six graduate instructors; five were involved in the focus-group interviews. From attending the large lecture sessions, they were able to assess multimedia from a different perspective than the students. We also interviewed the graduate instructors because they were able to offer their impressions about how students react to multimedia, and because some have used multimedia in their own recitation sections.

A major theme in their responses was the need to balance between reaping the benefits of multimedia and increasing interaction between students and professor. The general consensus among the graduate instructors was that multimedia presentation should not be used too extensively, even in the large lecture halls. To reach students, they recommend that instructors occasionally turn off the computers and interact with students. Not only does mixing up presentation strategies allow more classroom interaction, it also prevents students from getting bored.

The graduate instructors also demonstrated their awareness of the time constraints of developing multimedia presentations. As explained by one graduate instructor:

You have to weigh the costs and benefits of spending three hours on the computer trying to make up a 20 minute presentation. You might be just as effective with...a couple of overheads and a little group discussion.... So when you talk about effectiveness, it is good when it is used (because) there is no other way.

Another instructor commented that she would like to use multimedia in her classes, but is worried about the time commitment:

I would like to do it, because I have ideas, but how much time would I have to spend? It is not that I do not want to do it, but if that becomes the standard, then you feel like you have to put on a big show every week.

The discussion about the time commitment needed to create multimedia presentations demonstrated, in their view, the need for a teaching assistant of their own. The professor also mentions the need for a multimedia "gopher" to assist in creating presentations.

All graduate instructors agreed that they plan on using computer-based multimedia when they teach independently. After agree- 
ing with her peers about plans to implement multimedia into her future classes, one graduate instructor discussed how she viewed instructors using multimedia as having added responsibilities:

Before you become computer literate, computers are a really scary thing. And a lot of students, myself included, are scared of being involved with computers and technology. I think that part of our job as instructors, if we use this in the classroom, is to make it fun, or give it the impression of being fun....At least attempt to encourage students to get involved with computers and technology as well. I think that is as important as an instructor.

\section{Students' Interests}

Because we gear instructional presentations to students, we conclude with their perspectives. Of first note is the low participation in the voluntary focus groups for the fall 1996 classes. Thirty-six randomly selected students were invited by letter from the two courses to participate in discussion groups concerning their attitudes toward large lecture courses and the use of multimedia. Of the 36 invited, only 3 participated. During the spring courses, we took an alternate approach by conducting focus groups during two regularly scheduled recitation meetings.

The low participation rate for the fall focus groups can be attributed to a number of factors, including student interest levels and time conflicts. The largest problem appears to be that most students were 18 years of age, which on our campus requires written parental permission for study participation. Securing permission from a parent or guardian discouraged many students from participation. As recorded in the professor's journal:

It is hard to pinpoint the recruitment method (no incentives offered by us, complicated letters of consent for underage students) or the stunning lack of interest and connection to the class as the culprit.

Graduate instructors also discussed the lack of student interest. With the exception of complaints about conventional overheads, few if any, students initiated comments about computer-aided presentations to their graduate instructors. One graduate instructor commented on the lack of student response:

I think they are ambivalent. I really think that as long as you are not up there talking for 40-50 minutes in a monotone voice, and not putting anything up at all...they will not complain. But honestly, not one of them made any comments about multimedia last semester.

Other graduate instructors supported this view. A graduate instructor offered an alternative view, attributing the lack of input from students to the fact that they are new to the university system. Because the majority of the class members were first-year students, they may not have realized that computer-aided multimedia presentations are relatively new to the classroom. Students may assume that multimedia technology is the norm in college. One student expressed this view when talking about how much material was covered in the course: "I guess maybe that is the way it is in all college courses. I am new to this."

A few other themes from the 1996 and 1997 focus groups warrant mentioning. Although multimedia presentations seemed to help note-taking skills, students stressed the difficulty in writing down the contents of the computer overhead while listening to the professor. It appears that many students are more concerned with immediately copying the material on each computer overhead, rather than taking notes as the professor progresses through the topics. A student offered this advice to classmates:

[Multimedia] is good because you can put a lot of stuff up quickly. But it is bad in the same sense because most of the students feel like they have to copy everything down as it comes on the screen. They are writing frantically instead of trying to listen and absorb. The instructor puts a chart with just numbers and you can see people trying to write this stuff down as fast as they can when the instructor is just putting it up to explain what he is talking about. He isn't saying, "Know this number." The students have to realize that they don't 
have to write everything down. Sometimes just listening is better.

One clear theme was that students like the use of multimedia presentations, but such media have their "place." That place is in the large lecture hall. Because they have primarily seen such presentations used as a lecture aid, they did not associate its use in smaller classrooms. As one student said:

For the large lecture classes you need some sort of control. Something that is organized that the class can follow. But like my communications class, it is very personal. We do projects and we talk directly with the professor. That probably would not work well with the multimedia thing because it is not a big note taking class. It (the university) incorporates it in the areas it needs to, the bigger classes. And a lot of the intro classes where you are learning basics...where you have just got to get in the material so you can move on the next level...I think it is effective then. But once you get to the upper level classes where it is designed to be more personal, it is better not to have it.

One topic of discussion surfaced in a spring focus group, a group with very few first-year students. They compared the current use of multimedia in their introductory sociology class to upper-level chemistry and anatomy classes. While comparing multimedia's use in the different courses, some students concluded that computer technology was unnecessary in sociology classrooms. An upper-class student represents this perspective:

I don't think sociology, and the points it is trying to get across, need multimedia. The things we are learning, with the exception of maybe some videos, are pretty much lecture notes. When I sit in sociology I can pretty much take notes without even looking up. And in chemistry they use multimedia for a lot of different things... it is helpful. You do need to watch and make sure you know what is going on (in chemistry, etc.).

Most of the students, however, disagreed. Some students did see the use of instructional technologies in the introductory soci- ology course as limited, but understood that there were many other possibilities for its use. In response to this, another student stated:

I disagree with her because I think it is important to put the visual image up even if it is just for notes. A lot of time you will have an instructor that just rambles and rambles. You don't know what to write down. If the instructor puts up the main points it helps you with the note taking. Plus, one thing that I have noticed is that when we started the semester the instructor wasn't using the technology. He was using some overheads and you could not even see. Then when he started using the technology at least the font got blown up to the point where we could actually see it.

The overall assessment of multimedia by both students and graduate instructors was very positive. The consensus among both groups was that multimedia is a valuable educational tool that college classrooms should continue to use. In fact, at the end of each focus group, the question was raised if the university should continue updating classrooms with multimedia capabilities. The answer was a resounding "yes." The vast majority of surveyed students indicated that, when enrolling in large lecture classes, they would prefer to enroll in a course with multimedia. All graduate instructors claimed they would use the technology when they teach independently. Another example of the support for multimedia lies in the responses to the question about positive and negative aspects of multimedia classes. The positive responses were numerous, and when asked to describe the negatives, answers were often, "I really do not see any negative aspects to its use."

\section{DISCUSSION}

In comparing the use of static and dynamic multimedia presentations, we found no significant differences in student cognitive outcomes on course tests nor in survey items measuring student motivations and perceptions. However, we do compile rich descrip- 
tions of the process of bringing new multimedia techniques to the large lecture classroom for students, teaching assistants, and faculty members. Their unique standpoints in the classroom raise substantive issues for course development and delivery. We conclude, as did most study participants, that instructors can effectively use this technology in large lectures. Methods to enhance this use are discussed below.

\section{Closing the Gap}

We identified some general suggestions from students and graduate instructors on how best to close the gap between student and professor and how to develop multimedia in the future. Clearly, we must experiment widely in using the best of the machines and the best of human resources in the large lecture classroom. From Moore's journal, several themes stand out for course development in the future. Control over the environment and time to "set up" are major factors in negotiating access to multimedia classrooms on campus. If instructors are stacked on top of each other in order to use a small number of these rooms, they may lose their effectiveness. Another scarce resource affected by multimedia is the interaction time with the classroom teacher. The time before and between mass sessions of classes is one of the few times to "work the crowd" informally and break down distances (Sundgren 1991). Another scarce resource is outside time for multimedia preparation. Sammons (1994) and Solomon (1994) note the small percentage of faculty members who use such equipment and the high investment of time, resources, and training needed to create, evaluate, and revise such programs.

However, multimedia can be adapted over time to stimulate student interaction with the professor and with other students. Moore's journals noted two activities for future large lecture classes, and she adapted them for multimedia formats. First, each day's lecture will end with multimedia previews of two or three concepts for the next class lecture. Students will prepare a "minute lecture" from the textbook in their own words that includes (1) a definition and (2) an example of the current sociological concept. The professor will turn off the multimedia at two or more points during the lecture and request an example from a student volunteer (for extra credit).

Other activity can occur on a more intermittent basis. As a unit concludes, the professor will present a question on the screen-or a short video clip-to initiate a "dyadic encounter." Each student will turn to a student next to them and solve the puzzle or apply a model, and then share their solution with the class. The intent is to deliberately build into the media presentations some opportunities for student interaction. To some extent, we can programmatically address alienation and accessibility issues raised by all participants in the large lecture course.

In conclusion, all three participant groups offer positions that were similar on some levels and unique to their impressions on others. The general theme of the interviews, journal, and surveys is "I like it, but...", which reflects the mostly positive responses to multimedia in large classrooms, but also notes less than complete satisfaction. Students, graduate instructors, and the course professor freely offered critiques and suggestions for improvement, but no individual felt that multimedia should be abandoned for lack of evidence of direct outcomes on tests. They endorsed computer multimedia presentations as very useful educational tools that assisted students in cognitive skills, taking notes, grasping sociological concepts, and generally keeping students motivated to focus on the material. The professor and graduate instructors viewed multimedia as an important tool for class redevelopment and improvement of the substantive and organizing framework of the course. Each student interviewed and most students surveyed indicated that they would enroll for another course using multimedia presentations, each graduate instructor plans to incorporate it more extensively in their development as college instructors, and the pro- 
fessors are committed to using it again as a developmental tool.

The novelty of teaching with new multimedia technologies may be a confounding factor in our study not only for the students, but also for the instructor and for our research design. We do not know if improvements in teacher techniques over time (or improvements in technologies) might lessen the gaps between instructor and students. In a response to an early draft of this paper, a colleague pointed out that test banks currently used with introductory sociology texts are geared to the textbooks themselves and do not measure the enhanced content that might be presented in multimedia and that might "make the difference" in student comprehension and test results (Brinkerhoff 1997). We recommend that future tests of student cognitive outcomes that are linked to multimedia presentations must analyze distinct measures of those elements presented uniquely by the multimedia.

As Clark and Salomon (1986) point out, the study and development of educational technology is aimed at improving learning, not the "glorification of the media." They argue that researchers must ask not only how and why a medium operates in instruction and learning, but also why it should be used at all. We found no significant differences in test scores or survey items measuring motivation or attitudes when comparing our static and dynamic computer media styles. However, we remind the readers that we did not have specific test items to measure these outcomes. We did find that the participants in these large lecture courses want computer multimedia continued. Our research participants reported in interviews and journals that their cognitive and motivational experiences were enhanced, and they enthusiastically suggested some strategies for future multimedia course development.

\section{APPENDIX. FOCUS-GROUP QUESTIONS}

(1) Have any of you ever taken a class at UN-L that has used instructional technologies (multimedia) during a large portion of the course? If so, how did the use of multimedia differ in the other course?

(2) Focus on your current introductory sociology class. Does the use of multimedia materials (slides, film, charts, etc.) hold your attention and interest?

(3) Does the instructor present these multimedia materials in an organized, understandable manner, or were these materials ever distracting to you? Is this course more organized than those in which instructional technologies are not used?

(4) Were the multimedia materials helpful in clarifying your understanding of theories and concepts in the class?

(5) In your next large lecture course, would you prefer less instructional technology or more questions posed directly to the student?

(6) Multimedia was not used during the first portion of your class....Did you like that better, or do you prefer when it is used?

(7) Are the multimedia materials useful in assisting your note-taking activities for Sociology 101? How? Why?

(8) Do multimedia presentations improve your memory of important concepts and information? Do they make you more prepared for the exams?

(9) During a class lecture in which the professor utilizes instructional technologies, do you feel like you can ask the instructor questions, or for clarification, at any time?

(10) Do you think using instructional technologies in the classroom make an instructor more or less accessible before, during, and after the class?

(11) Are instructional technologies relied too heavily in this course? Not enough?

(12) Pretend for a moment that you are registering for next semester and you must take a large lecture course. If in the course bulletin you had a choice between two sections of the same course, and one used instructional technologies, and the other did not, which one would you register for? Why?

(13) All things considered, do you think that the use of instructional technologies added value to this course? 
Appendix con't.

(14) In general, would you categorize the use of multimedia presentations in the classroom as an effective educational tool or simply entertainment?

(15) Overall, do you think that the university should continue to invest in developing large multimedia classrooms? What are the benefits? What are the drawbacks?

(16) Did the use of instructional technologies waste valuable class time? That is, did the instructor spend so much time adjusting, running, or fixing the multimedia presentation that it did not seem worth the effort?

(17) Describe your general likes and dislikes regarding the use of multimedia in the classroom.

\section{REFERENCES}

Ansorge, Charles and Myra Wilhite. 1994. "Multimedia Instruction: Student and Faculty Perceptions." Office of the Senior Vice Chancellor of Academic Affairs, University of Nebraska, Lincoln, NE. Unpublished manuscript.

Berg, Bruce L. 1995. Qualitative Research Methods for the Social Sciences. 2d ed. Boston, MA: Allyn and Bacon.

Brinkerhoff, David B. 1997. Private communication. University of Nebraska-Lincoln.

Clark, Richard E. 1983. "Reconsidering Research on Learning from Media." Review of Educational Research 53:445-60.

Clark, Richard E. and Gavriel Salomon. 1986. "Media in Teaching." Pp. 472-85 in Handbook of Research on Teaching, by Merlin C. Wirrock. New York: MacMillan.

Dimitrova, Ganka, Caroline H. Persell, and Richard Maisel. 1993. "Using and Evaluating ISSE, a New Computer Program for Teaching Sampling and Statistical Inference." Teaching Sociology 21:341-51.

Henderschott, Anne and Sheila Wright. 1993. "Student Focus Groups and Curricular Review." Teaching Sociology 21:154-59.

King, Kim M. 1994. "Leading Classroom Discussions: Using Computers for a New Approach." Teaching Sociology 22: 174-82.

Kulik, J., Bangert R., and G. Williams. 1983. "Effects of Computer-Based Teaching on Secondary Students." Journal of Educational Psychology 75:19-26.

Lee, Motoko Y. and Charles Oulman. 1991. "Hypermedia for Classroom Use: A Complement to Use in the Laboratory." Teaching Sociology 19:510-13.

Lofland, John and Lyn H. Lofland. 1995. Analyzing Social Settings. 3d ed. Belmont, CA: Wadsworth.

Magnuson-Martinson, S. 1995. "Classroom Computerization: Ambivalent Attitudes and
Ambiguous Outcomes." Teaching Sociology 23:1-7.

McGee, Reece. 1991. "Practical Problems of Mass Instruction." Pp. 13-21 in Teaching the Mass Class, edited by Reece McGee. Washington, DC: American Sociological Association.

Mezirow, Jack and Associates. 1990. Fostering Critical Reflection in Adulthood. San Francisco, CA: Jossey Bass.

Neapolitan, Jerry. 1989. "A Test of Simple Computer-Assisted Instructional Software." Teaching Sociology 17:493-96.

Persell, Caroline H. 1992. "Bringing PCs into Introductory Sociology Courses: First Steps, Missteps, and Future Prospects." Teaching Sociology 20:91-103.

Pintrich, Paul R., D.A. Smith, T. Garcia, and W. McKeachie. 1993. "Reliability and Predictive Validity of the Motivated Strategies for Learning Questionnaire (MSLQ)." Journal of Educational Psychology and Measurement 53:801-13.

Reed-Sanders, D. and Steve Liebowitz. 1991. "An Empirical Test of Integration of Computers in Introductory Sociology." Teaching Sociology 19:223-30.

Sammons, Michael C. 1994. "Motivating Faculty to Use Multimedia as a Lecture Tool." T.H.E. Journal 21:88-90.

Solomon, Matthew B. 1994. "What's Wrong with Multimedia in Higher Education?" T.H.E. Journal 21:81-83.

Spencer, Ken. 1996. Media and Technology in Education. Liverpool: Manutius Press.

Stoloff, Michael. 1995. "Teaching Physiological Psychology in a Multimedia Classroom." Teaching of Psychology 22:138-41.

Sundgren, Ann S. 1991. "Working the Crowd: Organizing and Controlling the Mass Class." Pp. 48-53 in Teaching the Mass Class, edited by Reece McGee. Washington, DC. American Sociological Association. 
Timothy D. Pippert is a doctoral student at the University of Nebraska-Lincoln. His research interests include the areas of family, stratification, gender, and teaching technology. He served as instructional multimedia "guru" to the department of sociology in 1996 to 1997. His current research is on familial ties of the homeless.

Helen A. Moore is a professor of sociology at the University of Nebraska-Lincoln. She teaches in and has been chair of the departments of sociology and women's studies. She also teaches a required graduate seminar on college teaching and large introductory sociology courses. She also participates in summer undergraduate programs with the National Science Foundation, McNair Programs, and ASA Minority Opportunities through School Transformation. Her research interests include education, sex/gender, and inequality. 